\title{
Yapısal ve çevresel faktörlerin konut fiyatlarına etkisi: Ordu kent merkezi örneği
}

\author{
Mesut GÜZEL ${ }^{(D)}$, Pervin YEŞiL ${ }^{(\mathbb{D} 1}$, Elif Gülderen GÜZEL ${ }^{(D)}$ \\ 10rdu Üniversitesi, Ziraat Fakültesi Peyzaj Mimarlı̆̆ı Bölümü, 52200-Ordu
}

Alınış tarihi: 11 Mart 2020, Kabul tarihi: 15 Haziran 2020

Sorumlu yazar: Mesut GÜZEL, e-posta: mesutguzel@odu.edu.tr

\section{Öz}

$\mathrm{Bu}$ çalışmada Ordu Kent Merkezi'nde bulunan dairelerin satış fiyatını etkileyen yapısal ve çevresel faktörlerin neler olduğu ve bu faktörlerin satış fiyatlarını ne yönde etkilediği yarı-logaritmik hedonik fiyatlandırma modeli kullanılarak araştırılmıştır. Çalışmada 80 emlak ofisinden alınan veriler kullanılarak, 22 farklı mahalleden toplam 537 daire incelenmiștir. \%95 güven aralığında yapılan çok değişkenli regresyon analizi sonucunda, oluşturulan modele katılan 16 bağımsız değișkenden 5 tanesi $p<0.001,4$ tanesi $p<0.05$ düzeyinde istatistiksel olarak anlamlı bulunmuştur. Anlamlı bulunan 9 değişkenden 8'i daire fiyatlarını pozitif yönde etkilerken yalnızca biri negatif yönde etkilemiștir. Daire fiyatlarını olumlu yönde etkileyen en önemli değişkenler arasında; dairenin net büyüklüğü, ısıtma sistemi, denize yakınlı ve dairenin park manzarası görme durumu sayılabilir. Dairenin bulunduğu binanın yaşının fazla olması ise daire fiyatını negatif etkileyen anlamlı bir değişken olarak bulunmuştur.

Anahtar kelimeler: Hedonik fiyat modeli; Konut fiyatlandırma; Ordu; Türkiye

\section{Effects of structural and environmental factors on housing prices: The case of Ordu city center}

\author{
Abstract \\ In this study, the structural and environmental \\ factors affecting the sales price of the apartments in \\ Ordu City Center and how these factors affect the \\ sales prices were investigated using the semi- \\ logarithmic hedonic pricing model. In the study, \\ using the data obtained from 80 real estate offices, a \\ total of 537 apartments from 22 different \\ neighborhoods were examined. As a result of the
}

multivariate regression analysis performed in the $95 \%$ confidence interval, 5 of the 16 independent variables included in the model were found to be statistically significant at the level of $p<0.001$ and 4 at the level of $p<0.05$. While 8 of the 9 variables found significant affect the apartment prices positively, only one affected negatively. Among the most important variables that positively affect apartment prices; Net size of the apartment, heating system, proximity to the sea and the park view of the apartment can be counted. The age of the building where the apartment is located is found to be a significant variable that negatively affects the apartment price.

Keywords: Hedonic price model; Housing pricing; Ordu; Turkey

\section{Giriş}

Konut fiyatlarını etkileyen yapısal ve çevresel pek çok faktör bulunmaktadır. Konutların yapısal özellikleri, kent içerisindeki konumları, çeşitli odak noktalarına olan uzaklıkları, manzaraya sahip olup olmamaları, fiyatların değişiminde ve kent içerisinde heterojen bir yapı sergilemesinde en önemli etmenlerdendir. Barınma ihtiyacı ile başlayan ve günümüzde barınma ihtiyacının ötesinde yaşamı şekillendiren konutlar, Coşkun (2016)'a göre artık dayanıklı bir tüketim malı; bir yatırım alanı, sosyal statü ve güç göstergesi, sosyal kabul aracı haline gelmiştir. Dolayısı ile konutlar insanların barınma ihtiyacını karşılarken, aynı zamanda muhitin konumundan, konutun özelliklerine, yapı malzemesinden konutun bulunduğu sosyal tabakaya ve komşuluk (Keleş ve Atabeyli, 2018) gibi fonksiyonlara bağlı olarak ortaya koydukları tercihler ile konut piyasaları şekillenmektedir. Konut fiyatlarına etki eden faktörlerin belirlenmesinde ve fiyat tahminlerinin yapılmasında; hedonik fiyat 
modeli ve çoklu regresyon analizi yöntemi (Afşar ve ark., 2017; Çalmaşur ve Aysin, 2019; Güler ve ark., 2019; Kördiş ve ark., 2014; Yayar ve Bursal, 2019), yapay sinir ağları (YSA) yöntemi (Abidoye ve Chan, 2017; Ecer, 2014; Lim ve ark., 2016; Yllmazel ve ark., 2018), coğrafi ağırlıklı regresyon (GWR) (Dziauddin ve Idris, 2017; Lu ve ark., 2014; McCord ve ark., 2018), mekânsal ekonometrik modeller (Çelik ve Turgut, 2019; Uyar ve Yayla, 2016; Von Graevenitz ve Panduro, 2015) gibi pek çok yöntem uygulanmıştır. Bunlar içerisinde en fazla öne çıkan yöntemler olarak hedonik fiyat modeli ve çoklu regresyon analizinin birlikte kullanıldığı yöntem ile yapay sinir ağları (YSA) yöntemi karşımıza çıkmaktadır. Rosen (1974) tarafından geliştirilen hedonik fiyat yönteminin temelinde bir mal veya hizmetin sahip olduğu özelliklerinden dolayı tüketicisine sağladığı memnuniyet ve fayda yer alır. Konutların heterojen özelliklere sahip olması nedeniyle konut piyasası ile ilgili yapılan çalışmalarda hedonik fiyat modeli sıç̧a kullanılmaktadır (Yayar ve Bursal, 2019). Bu model belirli bir ürünün değerini o ürünün kendi özellikleri üzerinden ölçer (Çiçek ve Hatırll, 2015). Burada söz konusu ürün konut, ürünün özellikleri ise konutun sahip olduğu fiziksel özellikler ve konutun çevresiyle olan pozitif ya da negatif etkileşimidir. Hedonik fiyat yöntemi ile konutların sahip olduğu her bir özelliğin konut fiyatını nası etkilediği belirlenebilmektedir (Yiyit, 2017). Bir diğer yöntem olan yapay sinir ağları (YSA) yönteminde ise, insanın öğrenme sürecini taklit ederek oluşturulmuş bilgisayar sistemleri kullanılmaktadır. Bu sistemler kendilerine gösterilen örnekleri kullanarak eğitilebilen ve benzer konularda karar verebilen sistemlerdir (Ecer, 2014). Birçok çalışmada YSA, geleneksel regresyon yöntemleri ile birlikte uygulanmıș ve sonuçlar kıyaslanmıştır. YSA yöntemi genellikle geleneksel yöntemlere göre doğruluk oranı daha yüksek sonuçlar vermiștir. Ancak bu yöntem ile elde edilecek sonuçların sağlıklı ve doğruluğun yüksek olabilmesi için örneklem sayısının oldukça fazla olması (Yılmazel ve ark., 2018) ve doğru veri büyüklüğün̈n seçilmesi (Nghiep ve $\mathrm{Al}, 2001$ ) gerekmektedir.

$\mathrm{Bu}$ çalışmanın amacı; Ordu ilinde yoğun kentleşmenin görüldüğü 22 mahalledeki konutların satış fiyatına etki eden yapısal ve çevresel faktörlerin hedonik fiyat modeli kullanılarak belirlenmesidir. Kentleşmenin son yıllarda hız kazandığı Ordu ilinde konut fiyatlarını etkileyen faktörlerin belirlenmesi, kullanıcıların konut seçimindeki tercih ve eğilimlerini anlama noktasında önemli katkılar sağlayacaktır.

\section{Materyal ve Yöntem}

Çalışma alanı olarak Ordu ili Altınordu ilçesine bağlı ve yoğun yerleşimlerin bulunduğu 22 mahalle (Akyazl, Aziziye, Bahçelievler, Bucak, Cumhuriyet, Durugöl, Düz, Güzelyalı, Karapınar, Karşıyaka, Kirazlimanı, Kumbaşı, Nizamettin, Saray, Selimiye, Subaşı, Şahincili, Şarkiye, Şirinevler, Taşbaşı, Yeni, Zaferimilli) belirlenmiştir (Şekil 1). Bu mahallelerde daire, rezidans, müstakil ev, villa gibi farklı nitelikte konut tipleri bulunmaktadır. Çalışmada ise söz konusu mahallelerde hizmet sunan 80 emlak ofisinden alınan toplam 537 apartman dairesine ait veriler kullanılmıștır. Veriler Aralık 2019-Şubat 2020 arasındaki dönemi kapsamaktadır.

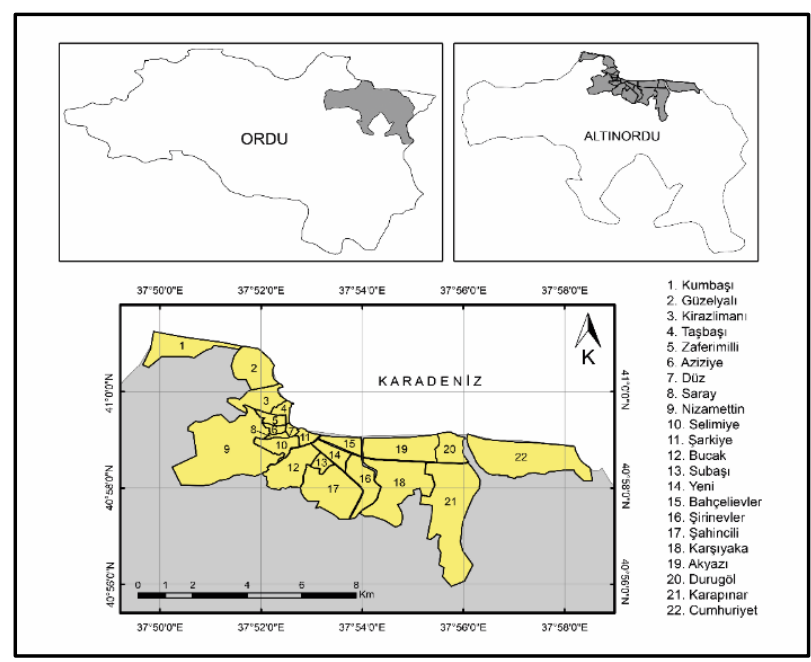

Şekil 1. Çalışma alanının konumu

Çalışmanın bağımlı değişkeni (FIYAT) ve diğer açıklayıcı bağımsız değişkenler, tanımları ve birimleri Çizelge 1'de verilmiştir. 10 değişken dairenin ve dairenin bulunduğu binanın yapısal karakteristiği ile ilişkilidir: dairenin bulunduğu mahalle (MAHALLE), dairenin net kullanım alanı büyüklüğü (BUYUKLUK), dairenin bulunduğu binadaki kat sayısı (KATSAYISI), dairenin bulunduğu kat (DAIREKAT), toplam oda ve salon sayisı (ODASAYI), dairenin gördüğü cephe sayısı (CEPHESAYISI), dairenin bulunduğu binanın yaşı (BINAYASI), dairenin site içerisinde yer alma durumu (SITEDURUMU), dairenin isitmasinda kullanılan sistem (ISITMA), dairede bulunan banyo sayısı (BANYOSAYISI). Diğer 6 değişken ise dairenin ve dairenin bulunduğu binanın çevresi ile olan bağlantılarla ilişkilidir: dairenin parklara yakınlığı 
(PARKYAKINLIK), dairenin denize yakınlığı (DENIZYAKINLIK), dairenin kent merkezine yakınlığı (KENTYAKINLIK), dairenin deniz manzarası görme durumu (DENIZMANZARA), dairenin park manzarası görme durumu (PARKMANZARA), dairenin anayollara olan yakınlı durumu (ANAYOLYAKINLIK).

Çizelge 1. Daire fiyatlarını etkilediği düşünülen yapısal ve çevresel değişkenler

\begin{tabular}{|c|c|c|c|}
\hline \multirow{12}{*}{ 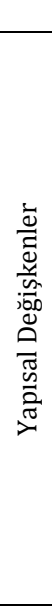 } & Değişken & Tanım & Birim \\
\hline & FIYAT & Dairenin satış fiyatı & TL \\
\hline & MAHALLE & Dairenin bulunduğu mahalle & $1-22^{\mathrm{a}}$ \\
\hline & BUYUKLUK & $\begin{array}{c}\text { Dairenin net kullanım alanı } \\
\text { büyüklüğü }\end{array}$ & $\mathrm{m}^{2}$ \\
\hline & KATSAYISI & $\begin{array}{l}\text { Dairenin bulunduğu binadaki } \\
\text { kat sayısı }\end{array}$ & adet \\
\hline & DAIREKAT & Dairenin bulunduğu kat & adet \\
\hline & ODASAYI & Toplam oda ve salon sayısı & adet \\
\hline & CEPHESAYISI & Dairenin gördüğü cephe sayısı & $1-4$ \\
\hline & BINAYASI & $\begin{array}{c}\text { Dairenin bulunduğu binanın } \\
\text { yașı }\end{array}$ & $1-7 \mathrm{~b}$ \\
\hline & SITEDURUMU & $\begin{array}{c}\text { Dairenin site içerisinde yer } \\
\text { alma durumu }\end{array}$ & $0-1$ \\
\hline & ISITMA & $\begin{array}{l}\text { Dairede kullanilan isitma } \\
\text { sistemi }\end{array}$ & $1-5^{\mathrm{c}}$ \\
\hline & BANYOSAYISI & $\begin{array}{c}\text { Dairede bulunan banyoların } \\
\text { sayısı }\end{array}$ & adet \\
\hline \multirow{6}{*}{ 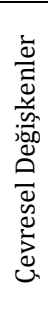 } & PARKYAKINLIK & Dairenin parklara yakınlığ ${ }^{\mathrm{d}}$ & $0-1$ \\
\hline & DENIZYAKINLIK & Dairenin denize yakınlığ $1^{\mathrm{e}}$ & $0-1$ \\
\hline & KENTYAKINLIK & $\begin{array}{c}\text { Dairenin kent merkezine olan } \\
\text { uzaklığı }\end{array}$ & $\mathrm{km}$ \\
\hline & DENIZMANZARA & $\begin{array}{l}\text { Dairenin deniz manzarası } \\
\text { görme durumu }\end{array}$ & $0-1$ \\
\hline & PARKMANZARA & $\begin{array}{l}\text { Dairenin park manzarası } \\
\text { görme durumu }\end{array}$ & $0-1$ \\
\hline & ANAYOLYAKINLIK & Dairenin anayollara yakınlığ ${ }^{\mathrm{f}}$ & $0-1$ \\
\hline
\end{tabular}

a 1.Nizamettin Mah., 2. Zaferimilli Mah., 3. Taşbaşı Mah., 4.Şarkiye Mah., 5.Aziziye Mah., 6.Düz Mah., 7.Saray Mah., 8.Kirazlimanı Mah., 9.Kumbaşı Mah., 10.Subaşı Mah., 11.Bahçelievler Mah., 12.Selimiye Mah., 13.Yeni Mah., 14.Güzelyalı Mah., 15.Karapınar Mah., 16.Şirinevler Mah., 17.Durugöl Mah., 18.Akyazı Mah., 19.Bucak Mah., 20.Karşıyaka Mah., 21.Cumhuriyet Mah., 22.Şahincili Mah.

b 1.0-4, 2.5-10, 3.11-15, 4.16-20, 5.21-25, 6.26-30, 7.31 ve üzeri.

c 1.Soba, 2.Doğalgaz sobası, 3.Merkezi sistem, 4.Yerden isitma, 5. Doğalgaz (Kombi).

d Dairenin 500 m yakınında park bulunuyorsa 1, bulunmuyorsa 0 değeri verilmiştir.

e Daireden en fazla $500 \mathrm{~m}$ mesafede denize ulaşllyyorsa 1, ulaşılmıyorsa 0 değeri verilmiştir.

f Dairenin en fazla $100 \mathrm{~m}$ yakınında anayol bulunuyorsa 1, bulunmuyorsa 0 değeri verilmiştir.

Açı-yeşil alanlara yakınlık ve rekreasyon olanaklarına ulaşılabilirlik konut seçiminde en etkili faktörlerdendir (Karadağ ve ark., 2019). Bu sebeple konutların fiyatı, parklar ile nehir ve göl gibi su yüzeylerine yakınlığı oranında artmaktadır (Wen ve ark., 2015). Konutların açık-yeşil alanlara ve çeşitli su yüzeylerine yakınlığıyla beraber konutun manzara sahipliğinin de satış fiyatını etkilediği bilinmektedir. Yapılan bir araştırmada orman manzaralı konutların, benzer özelliklere sahip diğer konutlara oranla ortalama \%4.9 daha pahalı olduğu belirlenmiştir (Tyrväinen ve Miettinen, 2000). Bu gibi etkilerin araștırma alanında da görülüp görülmediğini test etmek amaciyla dairelerin parklara (PARKYAKINLIK) ve denize (DENIZYAKINLIK) olan yakınlıkları ile herhangi bir park (PARKMANZARA) veya deniz (DENIZMANZARA) manzarası görme durumları birer değişken olarak belirlenmiş ve ikili kodlandırma (01) yapılmıştır. Ayrıca dairelerin bulvar ve cadde gibi anayollara yakınlı̆̆ı ile fiyat arasındaki ilişkinin sorgulanması amaciyla "ANAYOLYAKINLIK" değişkeni dâhil edilmiş ve ikili kodlandırma yapılmıştır. Dairelerin konumu ile ilgili açılklayıcı bir değişken olarak "KENTYAKINLIK" değişkeni belirlenmiştir. Ordu Büyükșehir Belediyesi binası, Ayışığı Otoparkı, Aziziye (Yalı) Cami gibi yapılar ile çevrili olan meydan; kentin toplanma-dağılma ve odak noktası olarak ilk akla gelen mekân olması nedeni ile kent merkezi olarak kabul edilmiș ve dairelerin bu meydana olan Öklid mesafesi sayısal haritalar üzerinden ölçülmüştür. Öklid mesafesi, bir harita üzerindeki iki nokta arasında çizilen çizginin uzunluğu olarak tanımlanır. P1 noktasına ait koordinatlar $\left(\mathrm{x}_{1}, \mathrm{y}_{1}\right)$ ve $\mathrm{P} 2$ noktasina ait koordinatlar $\left(\mathrm{x}_{2}, \mathrm{y}_{2}\right)$ olduğunda, iki nokta arasındaki Öklid mesafesi aşağıdaki formül ile hesaplanır (Jim ve Chen, 2006):

$\sqrt{\left(x_{1}-x_{2}\right)^{2}+\left(y_{1}-y_{2}\right)^{2}}$

Hedonik bir model için yapılan analizlerde genel olarak lineer (doğrusal), yarı logaritmik ve tam logaritmik fonksiyon kalıpları kullanılmaktadır (Yayar ve Gül, 2014). Bu çalışmada yarı-logaritmik model kullanılmıştır. Model şu şekilde formüle edilmiştir:

ln FIYAT $=\beta_{0}+\beta_{1} \ln$ MAHALLE $+\beta_{2} \ln$ BUYUKLUK + $\beta_{3} \ln$ KATSAYISI $+\beta_{4} \ln$ DAIREKAT $+\beta_{5} \ln$ ODASAYI + $\beta_{6} \ln$ CEPHESAYI $+\beta_{7} \ln$ BINAYAS $+\beta_{8}$ SITEDURUM + $\beta_{9}$ ln ISITMA $+\beta_{10}$ ln BANYOSAYI $+\beta_{11}$ PARKYAKINLIK $+\beta_{12}$ DENIZYAKINLIK $+\beta_{13} \ln$ KENTYAKINLIK $+\beta_{14}$ DENIZMANZARA $+\beta_{15}$ PARKMANZARA $+\beta_{16}$ ANAYOLYAKINLIK.

Formülde $\beta_{0}$ sabit ve $\beta_{1}-\beta_{16}$ fiyat değişkeninin doğal logaritmasını etkileyen diğer bağımsız değişkenleri ifade etmektedir. İkili kodlandırma (0-1) yapılan değişkenler için logaritma dönüşümü yapılmamıştır. Belirlenen değişkenler doğrultusunda dairelere ait 
veriler emlak ofislerinden alınmıștır. Analizlerde oluşabilecek sapmalardan kaçınmak adına eşyalı daireler, müstakil konutlar ve iki katlı daireler araştırmaya dâhil edilmemiştir. Mesafe ölçümlerinde sayısal haritalardan ve Google Earth Pro yazılımından yararlanılmıştır. Yapılan ölçümler ve görsel değerlendirmeler sonucunda elde edilen veri seti ile SPSS 22 yazılımı ortamında çok değişkenli regresyon analizi yapılmış ve sonuçlar değerlendirilmiştir.

\section{Bulgular ve Tartışma}

Seçilen mahallelerdeki apartman dairesi fiyatları ve daire fiyatlarını etkilediği düşünülen yapısal ve çevresel değişkenlere ait tanımlayıcı istatistikler Çizelge 2'de verilmiştir. Çalışmanın materyalini oluşturan 537 dairenin \%13.78'i Cumhuriyet Mahallesi'nde, \%13.22'si Şahincili Mahallesi'nde, \%8.38'i Durugöl Mahallesi'nde, \%7.64'ü Karşıyaka
Mahallesi'nde, \%7.26'sı Şirinevler Mahallesi'nde, \%6.52'si Akyazı Mahallesi'nde, \%6.33'ü Bucak Mahallesi'nde, \%4.66'sı Güzelyalı Mahallesi'nde, \%4.66'sı Yeni Mahalle'de ve geriye kalan \%27.56's ise diğer 13 mahallede bulunmaktadır. Dairelerin mahallelere göre ortalama satış fiyatları Şekil 2'de görülmektedir. Buna göre ortalama satış fiyatının en fazla olduğu mahalleler Güzelyalı (412.347 TL), Bahçelievler (372.043 TL) ve Kirazlimanı (357.444 TL); en az olduğu mahalleler ise Subaşı (186.462 TL), Selimiye (187.729 TL) ve Şarkiye (213.333 TL) mahalleleridir. Dairelerin \%74.49'u $100 \mathrm{~m}^{2}$ ve üzeri net kullanım alanına sahipken geriye kalan $\% 25.51$ ' $\mathrm{i}$ $100 \mathrm{~m}^{2}$ altında net kullanım alanı sunmaktadır. Dairelerin bulunduğu apartmanların kat sayısı 1 ile 18 arasında değişmektedir. Dairelerin \%4.66'sı giriş katta, \%62.76'sı 1., 2. ve 3.katlarda, \%32.58'i ise 4.kat ve üzerinde yer almaktadır.

Çizelge 2. Yapısal ve çevresel değişkenlere ait tanımlayıcı istatistikler

\begin{tabular}{|c|c|c|c|c|c|}
\hline & Değișken & Ortalama & Aralık (min. - maks.) & Standart Sapma & $\mathrm{n}$ \\
\hline \multirow{11}{*}{ 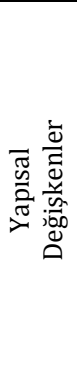 } & FIYAT & $282.284,81$ & $80.000-1.150 .000$ & $114.431,1660$ & 537 \\
\hline & MAHALLE & 16.11 & $1-22$ & 5.2528 & 537 \\
\hline & BUYUKLUK & 117.51 & $45-250$ & 28.4983 & 537 \\
\hline & KATSAYISI & 5.35 & $1-18$ & 2.3855 & 537 \\
\hline & DAIREKAT & 2.92 & $1-18$ & 2.2364 & 537 \\
\hline & ODASAYI & 3.64 & $2-6$ & 0.6582 & 537 \\
\hline & CEPHESAYISI & 2.46 & $1-4$ & 0.7790 & 537 \\
\hline & BINAYASI & 2.15 & $1-7$ & 1.4678 & 537 \\
\hline & SITEDURUMU & 0.35 & $0-1$ & 0.4769 & 537 \\
\hline & ISITMA & 4.80 & $1-5$ & 0.8144 & 537 \\
\hline & BANYOSAYISI & 1.34 & $1-3$ & 0.4810 & 537 \\
\hline \multirow{6}{*}{ 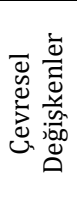 } & PARKYAKINLIK & 0.85 & $0-1$ & 0.3582 & 537 \\
\hline & DENIZYAKINLIK & 0.33 & $0-1$ & 0.4698 & 537 \\
\hline & KENTYAKINLIK & 2.82 & $0.27-7.57$ & 1.7421 & 537 \\
\hline & DENIZMANZARA & 0.21 & $0-1$ & 0.4106 & 537 \\
\hline & PARKMANZARA & 0.34 & $0-1$ & 0.4744 & 537 \\
\hline & ANAYOLYAKINLIK & 0.50 & $0-1$ & 0.5005 & 537 \\
\hline
\end{tabular}

Dairelerin \%32.77'si 2+1％58.66'sı 3+1，\%3.54'ü $4+1$ ve geriye kalan $\% 5.03$ 'ü ise $5+1$ şeklinde düzenlenmiştir. Dairelerin bulunduğu binaların \%48.23'ü 0-4 yaş arasında, \%20.3'ü 5-10 yaş arasında, \%13.78'i 11-15 yaş arasında, \%9.12'si 1620 yaş arasında, \%4.28'i 21-25 yaş arasında, \%2.98'i 26-30 yaş arasında ve $\% 1.31^{\prime} \mathrm{i}$ ise 31 yaș ve üzerindedir.

Dairelerin \%96.28'inde doğalgaz (kombi), doğalgaz sobası, merkezi isitma ve yerden isitma sistemleri bulunurken geriye kalan \%3.72'lik kısmı halen soba ile isıtılmaktadır. Dairelerin \%66.67'sinde 1 banyo, \%32.96'sinda 2 banyo ve \%0.37'sinde 3 banyo bulunmaktadır. Dairelerin \%84.92'sinden maksimum $500 \mathrm{~m}$ mesafede herhangi bir yeşil alana ulaşlabilmektedir. Ayrıca dairelerin \%34.08'inden yeşil alan manzarası görülebilmektedir. Dairelerin \%32.77'sinden maksimum $500 \mathrm{~m}$ mesafede denize ulaşılabilmektedir. Ayrıca dairelerin \%21.42'sinin herhangi bir penceresinden deniz manzarası görülebilmektedir.

Dairelerin șehir merkezine uzaklıklarına bakıldığında; çoğunluğunun (\%61.82) şehir merkezine 2001 metre ve üzeri uzaklıkta olduğu görülürken, bunu sirasıyla 1001-1500 m (\%13.22), $501-1000 \mathrm{~m}(\% 10.99), 1501-2000 \mathrm{~m}(\% 10.06)$ ve 0 $500 \mathrm{~m}$ (\%3.91) uzaklıktaki daireler izlemektedir.

Çalışma alanında daire başına düşen oda ve salon sayısı ortalama 3.64 ve banyo sayısı 1.34 olarak bulunmuştur. Dairelerin ortalama büyüklügü 117.51 $\mathrm{m}^{2}$ ve ortalama fiyatı ise yaklaşık 282.285 Türk Lirasıdır (Çizelge 2). 


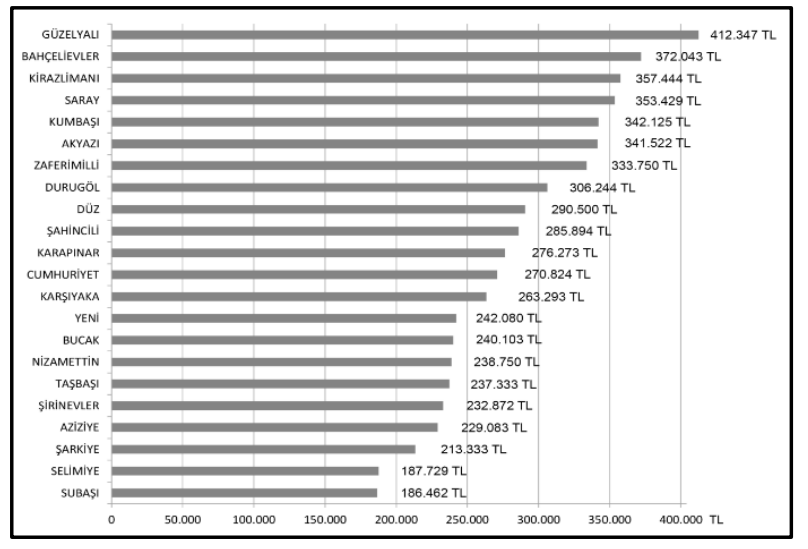

Şekil 2. Mahallelere göre dairelerin ortalama satış fiyatları

Daire satış fiyatları ile yapısal ve çevresel faktörler arasındaki ilişkiyi test etmek, hedonik fiyat modeli geliştirmek amaciyla çok değişkenli regresyon analizi kullanılmıştır. 1'i bağımlı değişken (ln FIYAT) ve 10'u yapısal 6'sı çevresel nitelikte 16 bağımsız değişken ile regresyon analizi yapılmıştır (Çizelge 3). Daha sonra istatistiksel olarak anlamlı bulunmayan değişkenler çıkarılarak tekrar regresyon analizi uygulanmıştır. Nihai sonuçlar Çizelge 4'te verilmiştir. Daire fiyatının doğal logaritması ile istatistiksel olarak anlamlı bağımsız değişkenler arasında kuvvetli bir ilişki olduğu gözlenmektedir. Literatüre göre, ikiden fazla bağımsız değişkenli regresyon modellerinde çoklu doğrusallık sorununun olmaması için genel kabul tolerans değerinin 0.4'ün üzerinde ve VIF değerinin 5'in altında olmasıdır (Adeboye ve diğ., 2014; Daoud, 2017). Analizin sonucunda ulaşılan Varyans Şişirme Faktörü (VIF-Varyans Inflation Factor) ve tolerans değerleri kabul edilebilir aralıktadır. $\mathrm{Bu}$ da değişkenler arasında çoklu bağlantı (multicollinearity) sorununun

Çizelge 3. Çok değişkenli regresyon analizi sonuçları bulunmadığını göstermektedir. Determinasyon katsayısı $\left(\mathrm{R}^{2}\right)$ modeldeki değişkenlerin daire satış fiyatındaki değişimin ne kadarını açıkladığı hakkında bilgi verir. Yapılan analize göre modele dâhil edilen değişkenler, daire fiyatlarındaki değişimin \%71'ini açıklamaktadır $\left(\mathrm{R}^{2}=0.713\right)$. Geçmişte yapılan benzer çalışmalarda farklı $\mathrm{R}^{2}$ değerleri bulunmuştur. Tyrväinen (1997) Finlandiya'nın Kuzey Karelya bölgesinde yaptığı çalışmada \%65, Jim ve Chen (2006) Çin'in Guangzhou kentinde yapılan çalışmada \%95, Yılmaz ve ark. (2008) Erzurum kentinde yapılan çalışmada \%55, Sander ve Polasky (2009) tarafinda A.B.D'nin Minnesota eyaletinde yapılan çalışmada \%79, Yayar ve Karaca (2014) tarafından Tokat, Amasya, Çorum ve Samsun kentlerini içine alan TR83 bölgesinde yapılan çalışmada \%58, Afşar ve ark. (2017) Eskişehir'de yaptığı çalışmada \%84, Özalp ve Akıncl (2017) tarafından Artvin Ortamahalle'de yapılan çalışmada ise \%84 değeri bulunmuştur. Yapılan ANOVA testinde $\mathrm{F}$ değeri 145.669 ve istatistiksel anlamlılık değeri 0.000'dır $(p<0.05) . \mathrm{Bu}$ da oluşturulan modelin istatistiksel olarak anlamlı olduğunu göstermektedir. Analize katılan 16 bağımsız değişkenden 5 tanesi $p<0.001$ seviyesinde, 4 tanesi ise $p<0.05$ seviyesinde istatistiksel olarak anlamlıdır (Çizelge 4). Anlamlı bulunan bağımsız değișkenlerden 8 tanesi (daire büyüklüğü, dairenin bulunduğu kat, dairenin site içerisinde yer alıp almama durumu, dairenin ısıtılmasında kullanılan sistem, dairede bulunan banyo sayısı, dairenin denize ve anayola yakınlığı, dairenin park manzaralı olması) daire fiyatlarını pozitif yönde, 1 tanesi (bina yașı) ise negatif yönde etkilemektedir.

\begin{tabular}{|c|c|c|c|c|c|}
\hline & Değișken & Katsayı & Std. Hata & $t$ & Anlamlılık \\
\hline \multirow{10}{*}{ 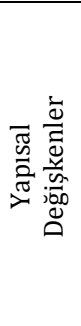 } & MAHALLE & -0.009 & 0.023 & -0.379 & 0.705 \\
\hline & BUYUKLUK & 0.854 & 0.065 & 13.122 & $0.000^{* *}$ \\
\hline & KATSAYISI & -0.018 & 0.031 & -0.591 & 0.555 \\
\hline & DAIREKAT & 0.035 & 0.015 & 2.278 & $0.023^{*}$ \\
\hline & ODASAYI & 0.101 & 0.082 & 1.228 & 0.220 \\
\hline & CEPHESAYI & -0.040 & 0.028 & -1.423 & 0.155 \\
\hline & BINAYAS & -0.135 & 0.019 & -7.178 & $0.000^{* *}$ \\
\hline & SITEDURUM & 0.069 & 0.026 & 2.647 & $0.008^{*}$ \\
\hline & ISITMA & 0.123 & 0.030 & 4.056 & $0.000^{* *}$ \\
\hline & BANYOSAYI & 0.097 & 0.035 & 2.778 & $0.006^{*}$ \\
\hline \multirow{7}{*}{ 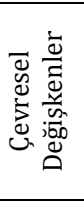 } & PARKYAKINLIK & 0.022 & 0.026 & 0.834 & 0.405 \\
\hline & DENIZYAKINLIK & 0.129 & 0.023 & 5.709 & $0.000^{* *}$ \\
\hline & KENTYAKINLIK & 0.007 & 0.017 & 0.408 & 0.683 \\
\hline & DENIZMANZARA & 0.022 & 0.026 & 0.847 & 0.397 \\
\hline & PARKMANZARA & 0.085 & 0.023 & 3.760 & $0.000 * *$ \\
\hline & ANAYOLYAKINLIK & 0.057 & 0.019 & 2.996 & $0.003^{*}$ \\
\hline & Sabit & 8.072 & 0.239 & 33.756 & 0.000 \\
\hline
\end{tabular}


Çalıșma kapsamında anlamlı bulunan değişkenlerin kullanıldığı çalışmalar birlikte değerlendirildiğinde; daire büyüklüğü faktörünün karşılaştırılan tüm çalışmalarda da anlamlı olarak belirlendiği görülmektedir. Diğer faktörler ise yer yer diğer çalıșmalarla örtüşmektedir (Çizelge 5). Elde edilen bulgular, diğer çalışmalarla benzer özellik göstermektedir. Ortaya çıkan farklılıklar ise çalışmaların kapsamı, çalışma alanlarının sosyal ve fiziksel özelliği ile ilgili olarak görülmektedir. Yerleşimlerin karakteristiği ile bu karakteristiği belirleyen tüm doğal ve kültürel faktörler, fiyatları etkileyen değişkenleri ortaya koymaktadır. Örneğin soğuk iklim koşullarının hâkim olduğu bir yörede balkon sayısı ve büyüklügünün etkili bir faktör olması beklenmez. Eğer kent içerisinde ya da yakın çevresinde herhangi bir su yüzeyi (deniz, göl, nehir, dere vb.) varsa, konut fiyatlarını etkileme anlamında önemli bir değişken haline gelmektedir. Deniz, göl ya da akarsu kıyısı yerleşmeler, kent sakinleri için en önemli tercih nedenlerini oluşturmakta ve bu bölgelerde konut fiyatlarının yükselmesine sebep olmaktadır. Bu örnekler çok geniş perspektifte çeşitlendirilebilir. Özetle, yapılan çalışmalar farklı özelliklere sahip yerleşimlerde gerçekleştirildiğinden konut fiyatlarına etki eden faktörler farklılaşabilmektedir.

Çizelge 4. İstatistiksel olarak anlamsız bulunan değişkenler çıkarıldıktan sonra elde edilen regresyon sonuçları

\begin{tabular}{ccccc}
\hline Değişken & Katsayı & Std. Hata & $t$ & Anlamlılık \\
\hline BUYUKLUK & 0.910 & 0.041 & 21.992 & $0.000^{* *}$ \\
DAIREKAT & 0.034 & 0.014 & 2.423 & $0.016^{*}$ \\
BINAYAS & -0.138 & 0.017 & -7.899 & $0.000^{* *}$ \\
SITEDURUM & 0.060 & 0.023 & 2.612 & $0.009^{*}$ \\
ISITMA & 0.122 & 0.030 & 4.027 & $0.000^{* *}$ \\
BANYOSAYI & 0.092 & 0.034 & 2.663 & $0.008^{*}$ \\
DENIZYAKINLIK & 0.139 & 0.020 & 6.907 & $0.000^{* *}$ \\
PARKMANZARA & 0.092 & 0.021 & 4.268 & $0.000^{* *}$ \\
ANAYOLYAKINLIK & 0.055 & 0.018 & 3.051 & $0.002^{*}$ \\
Sabit & 7.883 & 0.189 & 41.600 & 0.000
\end{tabular}

$\mathrm{R}^{2}=0.713$, ayarlanmıs $\mathrm{R}^{2}=0.708, F=145.669, n=537$.

Bağımlı değişken: ln FIYAT

* $p<0.05,{ }^{* *} p<0.001$

Çizelge 5. Analizde anlamlı bulunan değişkenler ile önceki çalışmalardaki benzer değişkenlerin kıyaslanması

\begin{tabular}{|c|c|c|c|c|c|c|c|}
\hline & $\begin{array}{c}\text { Tyrväinen } \\
\text { (1997) }\end{array}$ & $\begin{array}{c}\text { Jim ve Chen } \\
(2006)\end{array}$ & $\begin{array}{c}\text { Jim ve Chen } \\
\text { (2009) }\end{array}$ & $\begin{array}{l}\text { Yilmaz ve ark. } \\
\qquad(2008)\end{array}$ & $\begin{array}{c}\text { Yayar ve Gül } \\
(2014)\end{array}$ & $\begin{array}{c}\text { Yayar ve } \\
\text { Karaca } \\
(2014)\end{array}$ & $\begin{array}{l}\text { Afşar ve ark. } \\
\text { (2017) }\end{array}$ \\
\hline BUYUKLUK & $\checkmark$ & $\checkmark$ & $\checkmark$ & $\checkmark$ & $\checkmark$ & $\checkmark$ & $\checkmark$ \\
\hline DAIREKAT & - & $\checkmark$ & $\checkmark$ & - & - & $\checkmark$ & - \\
\hline BINAYAS & $\checkmark$ & - & $\mathrm{X}$ & $\checkmark$ & $\checkmark$ & $\mathrm{X}$ & - \\
\hline SITEDURUM & - & - & - & - & $\checkmark$ & - & - \\
\hline ISITMA & - & - & - & $\checkmark$ & - & $\checkmark$ & $\checkmark$ \\
\hline BANYOSAYI & - & $\checkmark$ & - & - & $\checkmark$ & $\checkmark$ & $\checkmark$ \\
\hline DENIZYAKINLIK & $\checkmark$ & $\checkmark$ & $\mathrm{X}$ & - & $\checkmark$ & - & - \\
\hline PARKMANZARA & - & - & - & - & - & - & - \\
\hline ANAYOLYAKINLIK & - & - & - & $\checkmark$ & - & - & - \\
\hline$\checkmark$ & \multicolumn{7}{|c|}{ Çalıșmada bu değișken daire satıș fiyatını etkileyen anlamlı bir değișken olarak bulunmuștur. } \\
\hline- & \multicolumn{7}{|c|}{ Çalışmada bu değişken kullanılmamıştır. } \\
\hline $\mathrm{X}$ & \multicolumn{7}{|c|}{ Çalıșmada bu değişken daire satış fiyatını etkileyen anlamlı bir değişken olarak bulunmamıştır. } \\
\hline
\end{tabular}

\section{Sonuç}

Ordu Kent Merkezi'nde yürütülen bu çalışma sonucunda; dairenin net kullanım alanının fazla olması, dairenin yüksek katlarda bulunması, dairede birden fazla banyo olması, isıtma sistemi olarak soba yerine doğalgaz ve yerden ısıtma sistemlerinin kullanılması, dairenin site içerisinde yer alması, dairenin denize ve anayola yakın olması ve park manzarası daire fiyatlarını arttırıcı etki gösterirken, dairenin bulunduğu binanın yaşının fazla olması fiyat üzerinde azaltıcı bir etki göstermiștir. Bununla birlikte; dairenin bulunduğu mahalle, kent merkezine ve park alanlarına yakınlı, dairenin gördüğü cephe sayısı, deniz manzarası, binanın kat sayısı ve dairenin sahip olduğu oda sayısı değişkenleri ile dairenin satış fiyatı arasında istatistiksel olarak anlamlı bir ilişki bulunmamıştır. Yapılan pek çok çalışmada olduğu gibi, bu çalışmada da net kullanım alanı, konut fiyatını etkileyen bir faktördür. Daire satış fiyatları ve belirlenen değişkenler arasındaki ilişkiyi test etmek amacıyla yapılan çok değişkenli regresyon analizine göre dairenin net kullanım alanı büyüklügü, fiyatı $\% 91$ oranında etkilemektedir. Yine dairede ısıtma sistemi olarak doğalgaz ve yerden isitma sistemlerinin bulunması sobalı dairelere göre fiyatta \%12.2'lik bir artışa neden olmakta, dairenin bulunduğu kat fiyatı \%3.4 oranında etkilemekte ve dairenin bulunduğu 
binanın yaş aralığı arttıkça satış fiyatı \%13.8 oranında düşmektedir. Kentte son yıllarda artış gösteren site yerleşkeleri, kent sakinlerinin tercih nedeni olmakta, yoğun yerleşimlerden uzak, güvenli, sakin ve nispeten daha ferah yaşam olanağı olarak görülmektedir. Çalışma ile de bu tercihin konut fiyatlarının artışına neden olduğu görülmekte ve dairenin site içinde yer alıp almaması \%6 oranında etkili olmaktadır. Ordu kenti sakinleri için kentin kuzey sınırını baştan başa kat eden Karadeniz kıyısında yer alan konutlarda yaşamak önem arz etmekte, bu tercih konut fiyatlarında da önemli düzeyde artışa neden olmaktadır. Öyle ki yapılan çalışmada, en fazla $500 \mathrm{~m}$ mesafede denize ulaşılabilen dairelerin fiyatının ulaşılamayan dairelerin fiyatından ortalama \%13.9 daha yüksek olduğu tespit edilmiștir. Bununla birlikte deniz kıyısının kuzeyde yer alması, kentlilerin bazıları için kuzey cephede deniz manzarası tercihi, bazıları için ise daha çok güneş alan ve daha rahat ısınan güney cephe tercihi olarak çeșitlenmekte ve dolayısı ile bu kentte bakı faktörünün konut fiyatını artıran bir değişken olmaması sonucunu ortaya çıkarmakta, benzer şekilde dairenin gördüğü cephe sayısı da konut fiyatını önemli ölçüde etkilememektedir.

Konutun bulunduğu mahalle değişkeni, Ordu kentinde önemsiz olarak belirlenmiștir. Kentin en eski yerleşmelerinin yer aldığı, günümüzde alışveriş ve yaya bölgelerinin odak oluşturduğu bölgede yer alan kent merkezine yakın mahallelerde genellikle nüfus yoğunluğunun fazla olması, dar sokaklar ve birbirine yakın konumlanmış eski binaların bulunması nedeni ile konut fiyatları yüksek değildir.

Yapılan çalışmalarda Ordu kenti mevcut parklarının etkili hizmet alanlarının bulundukları mahalleleri büyük oranda kapsadığı ve erişilebilir oldukları görülmüştür (Atabeyoğlu ve Bulut, 2012; Beyli ve Yeșil 2020). Parkların konut dokuları arasında erişilebilir mesafelerde dağılmış olması park alanlarına yakınlık faktörünün fiyatlar üzerinde etkili olmaması sonucunu doğurmuştur.

Ordu kenti, kıyı kenti olması nedeni ile denize paralel konumlanmıştır ve kenti ortadan bölen D010 karayolu, kent ulaşımının omurgasını oluşturmaktadır. Kent içerisinde de farklı yoğunluklarda, birbirini genellikle dik kesen yollar hâkimdir. Kentte yola yakınlık değişkeninin konut fiyatları üzerinde etkili bir faktör olduğu ve aynı özelliklere sahip iki daireden anayollara yakın olanın, yakın olmayan daireye göre \%5.5 daha pahalı olduğu görülmektedir. Manzara sahipliği de konut fiyatlarını etkileyen önemli faktörlerdendir. Ordu kent halkı, geçmişte merkez yerleşmelerde yaşadığı yoğunluk ve sıkışıklığın ardından, günümüzde kent odağının kısmen ötesinde ama merkezi konumlarda yer alan ve yapılaşmaların devam ettiği, merkeze göre kısmen daha ferah mahallelere doğru kayma eğilimindedir. $\mathrm{Bu}$ yerleşimler yapılaşmanın henüz tamamlanmadığı bölgeler olup, açık ve yeşil alanlara sahiptir. Ayrıca geniş park alanlarının da bulunduğu görülmektedir. Aynı özelliklere sahip daireler mukayese edildiğinde, park ya da herhangi bir yeşil alan gören bir dairenin fiyatı, görmeyen bir daireye göre \%9.2 oranında daha yüksektir.

\section{Kaynaklar}

Abidoye, R. B., \& Chan, A. P. (2017). Modelling property values in Nigeria using artificial neural network. Journal of Property Research, 34(1), 36-53.

Adeboye, N. O., Fagoyinbo, I. S., \& Olatayo, T. O. (2014). Estimation of the effect of multicollinearity on the standard error for regression coefficients. Journal of Mathematics, 10(4), 16-20.

Afşar, A., Yılmazel, Ö., \& Yılmazel, S. (2017). Konut fiyatlarını etkileyen faktörlerin hedonik model ile belirlenmesi: Eskişehir örneği. Selçuk Üniversitesi Sosyal Bilimler Enstitüsü Dergisi, 1(37), 195-205.

Atabeyoğlu, Ö., \& Bulut, Y. (2012). Ordu kenti mevcut yeşil alanlarının değerlendirilmesi. Akademik Ziraat Dergisi, 1(2), 67-76.

Beyli, K. N., \& Yeşil, M. (2020). Ordu kenti parklarının yeterlik ve ulaşılabilirliği üzerine bir araştırma. Gümüşhane Üniversitesi Fen Bilimleri Enstitüsü Dergisi, 10(2), 492-504.

Coşkun, Y. (2016). Konut fiyatları ve yatırımı: Türkiye için bir analiz. Niğde Üniversitesi İktisadi ve Ídari Bilimler Fakültesi Dergisi, 9(2), 201-217.

Çalmaşur, G. \& Aysin, M. E. (2019). Konut fiyatlarına etki eden faktörlerin hedonik modelle belirlenmesi: TRA1 alt bölgesi üzerine bir uygulama. Uluslararası Íktisadi ve Ídari Íncelemeler Dergisi, 1(22), 77-92.

Çelik, I.., \& Turgut, E. (2019). Antalya ilinde konut fiyatlarına etki eden faktörlerin mekânsal ekonometri ile incelenmesi. Uluslararası Ekonomik Araştırmalar Dergisi, 5(1), 39-48.

Çiçek, U., \& Hatırll, S. (2015). Isparta ilinde konut fiyatlarını etkileyen faktörlerin hedonik fiyat modeli ile analizi. Mehmet Akif Ersoy Üniversitesi Sosyal Bilimler Enstitüsü Dergisi, 7(13), 98-114

Daoud, J. I. (2017). Multicollinearity and regression analysis. In Journal of Physics: Conference Series (Vol. 949, No. 1, p. 012009). IOP Publishing.

Dziauddin, M. F., \& Idris, Z. (2017). Use of geographically weighted regression (GWR) method to estimate the effects of location attributes on the residential. 
property values. The Indonesian Journal of Geography, 49(1), 97-110.

Ecer, F. (2014). Türkiye'deki konut fiyatlarının tahmininde hedonik regresyon yöntemi ile yapay sinir ağlarının karşılaștırılması. International Conference On Eurasian Economies (pp. 1-10).

Güler, İ., Başer, U., \& Bozoğlu, M. (2019). Rize ili merkez ilçesinde konut fiyatlarının hedonik fiyat modeliyle değerlemesi. Iğdır Üniversitesi Fen Bilimleri Enstitüsü Dergisi, 9(4), 2294-2302.

Karadağ, A. A., Gültekin, Y. S., \& Mutlu, S. (2019). Açık ve yeșil alanların konut seçimine etkisinin belirlenmesi temelinde bir ölçek geliştirme çalışması. Düzce Üniversitesi Bilim Teknoloji Dergisi, 7(1), 223-238.

Keleş, Ş., \& Atabeyli, O. C. (2018). Konut ve hedonik fiyat bir yapısal eşitlik modeli uygulaması. The International New Issues in Social Sciences, 6(2), 111-128.

Jim, C. Y., \& Chen, W. Y. (2006). Impacts of urban environmental elements on residential housing prices in Guangzhou (China). Landscape and Urban Planning, 78(4), 422-434.

Jim, C. Y., \& Chen, W. Y. (2009). Value of scenic views: Hedonic assessment of private housing in Hong Kong. Landscape and Urban Planning, 91(4), 226234.

Kördiș, G., Sayım, I., \& Mert, M. (2014). Antalya'da konut fiyatlarını etkileyen faktörlerin hedonik fiyat modeli ile tahmin edilmesi. Akdeniz Üniversitesi Íktisadi ve Ídari Bilimler Fakültesi Dergisi, 14(28), 103-132.

Lim, W. T., Wang, L., Wang, Y., \& Chang, Q. (2016). Housing price prediction using neural networks. In 2016 12th International Conference on Natural Computation, Fuzzy Systems and Knowledge Discovery (pp. 518-522).

Lu, B., Charlton, M., Harris, P., \& Fotheringham, A. S. (2014). Geographically weighted regression with a non-Euclidean distance metric: a case study using hedonic house price data. International Journal of Geographical Information Science, 28(4), 660-681.

McCord, M. J., MacIntyre, S., Bidanset, P., Lo, D., \& Davis, P. (2018). Examining the spatial relationship between environmental health factors and house prices. Journal of European Real Estate Research, 11(3), 353-398.

Nghiep, N., \& Al, C. (2001). Predicting housing value: A comparison of multiple regression analysis and artificial neural networks. Journal of Real Estate Research, 22(3), 313-336.

Ozalp, A. Y., \& Akinci, H. (2017). The use of hedonic pricing method to determine the parameters affecting residential real estate prices. Arabian Journal of Geosciences, 10(24), 535.

Rosen, S. (1974). Hedonic prices and implicit markets: product differentiation in pure competition. Journal of Political Economy, 82(1), 34-55.

Sander, H. A., \& Polasky, S. (2009.) The value of views and open space: Estimates from a hedonic pricing model for Ramsey County, Minnesota, USA. Land Use Policy, 26(3), 837-845.

Tyrväinen, L. (1997). The amenity value of the urban forest: an application of the hedonic pricing method. Landscape and Urban Planning, 37(3-4), 211-222.

Tyrväinen, L., \& Miettinen, A. (2000). Property prices and urban forest amenities. Journal of Environmental Economics and Management, 39(2), 205-223.

Uyar, S. G. K., \& Yayla, N. (2016). Konut Fiyatlarının Hedonik Fiyatlama Yaklaşımına Göre Mekânsal Ekonometrik Modeller İle Tahmini: İstanbul Konut Piyasası Örneği. Social Sciences, 11(4), 326-342.

Von Graevenitz, K., \& Panduro, T. E. (2015). An alternative to the standard spatial econometric approaches in hedonic house price models. Land Economics, 91(2), 386-409.

Wen, H., Zhang, Y., \& Zhang, L. (2015). Assessing amenity effects of urban landscapes on housing price in Hangzhou, China. Urban Forestry \& Urban Greening, 14(4), 1017-1026.

Yayar, R., \& Bursal, M. (2019). Türkiye'de konut kira fiyatlarının hedonik tahmini. Insan ve Toplum Bilimleri Araştırmaları Dergisi, 8(3), 2010-2026.

Yayar, R., \& Gül, D. (2014). Mersin kent merkezinde konut piyasası fiyatlarının hedonik tahmini. Anadolu University Journal of Social Sciences, 14(3), 87-99.

Yayar, R., \& Karaca, S. S. (2014). Konut fiyatlarına etki eden faktörlerin hedonik modelle belirlenmesi: TR83 Bölgesi Örneği. Ege Academic Review, 14(4), 509518.

Yılmaz, H., Bulut, Z., Temurlenk, M. S., \& Yesil, P. (2008). Determination of the impact of parks and playgrounds on house prices in the city of Erzurum, Turkey. International Journal of Natural and Engineering Sciences, 2(1), 47-51.

Yılmazel, Ö., Afşar, A., \& Çiçek, A. (2018). Konut fiyat tahmininde yapay sinir ağları yönteminin kullanılması. Uluslararası Íktisadi ve Ídari Incelemeler Dergisi, 20, 285-300.

Yiyit, M. (2017). Isparta ilinde konut fiyatını etkileyen faktörlerin hedonik fiyat modeli ile belirlenmesi ve konut sektöründeki alt piyasaların örtük sınıf analizi ile açığa çıkarılması. (Doktora Tezi). Süleyman Demirel Üni Sosyal Bilimler Enstitüsü, Isparta. 